\title{
Clinical features and risk factors of pruritus in patients with chronic renal failure
}

\author{
TINGHAI HU ${ }^{1}$, BO WANG ${ }^{2}$, XIAOHUI LIAO ${ }^{1}$ and SHUXIANG WANG ${ }^{3}$ \\ Departments of ${ }^{1}$ Nephrology and ${ }^{2}$ Endocrinology, The Second Affiliated Hospital of \\ Chongqing Medical University, Chongqing, Sichuan 400010; ${ }^{3}$ Department of Outpatient, \\ Nanan People's Hospital of Chongqing, Chongqing, Sichuan 400060, P.R. China
}

Received September 11, 2018; Accepted November 26, 2018

DOI: $10.3892 / \mathrm{etm} .2019 .7588$

\begin{abstract}
Dermatological manifestations are common in systemic diseases, such as chronic kidney disease. The present study investigated the clinical features and possible influencing factors of pruritus in patients with chronic renal failure (CRF). A total of 382 inpatients were enrolled from the Department of Nephrology at The Second Affiliated Hospital of Chongqing Medical University. A total of 138 subjects were hemodialysis patients, 41 were peritoneal dialysis patients, and 203 were chronic renal failure patients. The patients' clinical performance was observed, and the data was recorded for analysis. The prevalence of pruritus in hemodialysis patients was greater than that in peritoneal dialysis patients. A total of 187 patients were accompanied by xerodermia and 109 patients had pruritus at the same time. With effective and regular dialysis, pruritus could be alleviated in $40 \%$ of patients. The intensity of pruritus in the enrolled patients ranged from mild itching to irritability during day and night periods. Moreover, pruritus was intermittent or persistent, and/ or limited to generalized. Following treatment, $35 \%$ of patients had poor results. A significant difference was noted in the levels of serum urea nitrogen, creatinine, serum phosphorus, calcium x phosphorus, and parathyroid hormone (PTH) between patients with pruritus and non-pruritus. Xerodermia is a common skin manifestation in patients with chronic renal failure and is associated with the occurrence of pruritus. Local cold and heat stimulation can relieve pruritus to some extent, and adequate hemodialysis can also relieve itching.
\end{abstract}

\section{Introduction}

The majority of systemic diseases have different degrees of dermatological manifestations. Chronic kidney disease (CKD)

Correspondence to: Dr Shuxiang Wang, Department of Outpatient, Nanan People's Hospital of Chongqing, 34 Jiangnan Road, Chongqing, Sichuan 400060, P.R. China

E-mail: drwangshuxiang@163.com

Key words: chronic renal failure, pruritus, hemodialysis, peritoneal dialysis is one of the most common systemic diseases with multiple clinical signs. This disease can cause multiple complications over time, especially in patients with comorbidities who require appropriate treatment $(1,2)$. For example, several diseases such as hyperlipidemia associated with non-alcoholic fatty liver disease (3), anemia associated with vitamin K-dependent coagulopathies and iron deficiency (4) or infections with bacteria and fungi (these activate mast cells) resistant to treatment, develop as a result of immunosuppression (5).

In severe non-alcoholic liver disease, the mechanism is not fully elucidated, but some studies have suggested that one of the possible mechanisms of pruritus in these conditions is histamine-mediated hepatocyte related involvement and associated with elevation of aspartate aminotransferase levels (6).

Skin pruritus is one of the most characteristic clinical symptoms in patients with end-stage-renal disease (ESRD) and uremia (7). The majority of the patients with uremia suffer from skin complications. Their incidence and severity increase with the progression of renal failure $(8,9)$. After clinical dialysis treatment, uremia is significantly alleviated (10), although the incidence of other comorbidities associated with uremia (such as porphyria cutanea tarda and skin tumors) gradually increased $(11,12)$. Skin pruritus can appear in all parts of the body, and the duration varies, leading to secondary scratches. The moss-like skin diseases such as nodular prurigo, seriously affect the patient's physical and mental health (13).

Depending on the site and pathogenesis of pruritus, it can be divided into skin-derived pruritus, neurogenic pruritus, pruritus associated with neuropathy, cardiogenic pruritus, and mixed pruritus $(14,15)$. For patients with end-stage renal disease, the mechanism of pruritus is more complex and may be the result of dysfunction of various organ systems (16). The present study evaluated the clinical features of skin pruritus, and investigated its relationship with several biochemical parameters. The aim was to provide theoretical background for the clinical treatment of this disease.

\section{Patients and methods}

Patients. From March 2015 to September 2017, 382 patients who were hospitalized in the Department of Nephrology, at the Second Affiliated Hospital of the Chongqing Medical 
University (Chongqing, China), were selected. The study protocol was approved by the Ethics Committee of the Second Affiliated Hospital of Chongqing Medical University (Chongqing, China), and all the patients signed an informed consent that allowed them to participate in the study. There were 225 males and 157 females and the average age of the subjects was $52.35 \pm 16.72$ years. The specific diagnostic criteria are shown in Table I.

When creatinine levels were higher than $707 \mu \mathrm{mol} / \mathrm{l}$ and the patient had clinical manifestations of uremia, dialysis treatment was performed. According to different renal replacement therapies, the patients were divided into two groups: hemodialysis group and continuous ambulatory peritoneal dialysis group.

Inclusion criteria: Patients with chronic renal failure and pruritus diagnosed by nephrologists were consistent with the diagnosis of chronic renal failure.

Exclusion criteria: Patients with poor compliance; patients with communication difficulties; patients with other pruritic skin diseases or other systemic diseases.

Clinical data collection. The demographic information (age, sex and educational level), personal history and family history of the target group was collected. The clinical parameters were obtained from each patient, including general treatment, hemodialysis, peritoneal dialysis, laboratory and auxiliary examination results, as well as blood urea, creatinine, serum calcium, serum phosphorus, and PTH values. The skin examination included color, dryness, desquamation, hair and skin integrity. The performance and characteristics of skin injuries were the following: xerodermia, manifested as dryness or desquamation of the whole body or local skin.

The patients with pruritus associated with chronic renal failure were diagnosed based on the following criteria: i) pruritus occurred at least 3 days in 12 weeks and itches were noted several times a day for several minutes each time; ii) pruritus occurred in a specific pattern lasting more than 1 month. The patients who presented with pruritus associated with other diseases were excluded from the group of those with CRF-associated pruritus.

Since pruritus is a subjective feeling of the patient and, obviously, there are individual differences, the severity of pruritus in the present study was assessed by the Visual Analogue Scale (VAS) parameter. The basic method is using a swimming scale with a length of approximately $10 \mathrm{~cm}$. One side is marked with 10 scales. Both ends are ' 0 ' and ' 10 ', respectively; 0 denotes no itching, and 10 denotes unbearable itching. During the evaluation, the scaled side is facing away from the patient and the patient states his/her degree of itchiness between 0 and 10 points according to his/her feeling.

Statistical analysis. The data obtained in the present study was analyzed using Excel and statistical software SPSS 19.0 (SPSS Inc., Chicago, IL, USA). The measurement data was expressed as mean \pm standard deviation (mean \pm SD) and the differences between groups were assessed using Student's t-test. Levene tests were used to analyze homogeneity of variance prior to the t-test. The Chi-square test was used for comparison of the numerical variables. When the risk factors were analyzed,
Table I. The specific diagnostic criteria.

\begin{tabular}{lc}
\hline Diagnostic staging & Index \\
\hline Renal insufficiency & GFR $(80-50 \mathrm{~m} 1 / \mathrm{min})$, \\
compensation period & Scr $(133-177 \mu \mathrm{mo} 1 / 1)$ \\
Renal insufficiency & GFR $(50-20 \mathrm{~m} 1 / \mathrm{min})$, \\
decompensation period & Scr $(178-445 \mu \mathrm{mo} 1 / 1)$ \\
Renal failure stage & GFR $(20-10 \mathrm{ml} / \mathrm{min})$, \\
& Scr $(446-707 \mu \mathrm{mo} 1 / 1)$ \\
Uremia stage & GFR $(<10 \mathrm{ml} / \mathrm{min})$, \\
& Scr $(>707 \mu \mathrm{mol} / 1)$
\end{tabular}

GFR, glomerular filtration rate; Scr, serum creatinine.

Table II. Xerodermia distribution among the patients.

\begin{tabular}{lcc}
\hline Symptom & Pruritus group & Non-pruritus group \\
\hline Xerodermia & 109 & $80^{\mathrm{a}}$ \\
No xerodermia & 88 & 105 \\
\hline
\end{tabular}

${ }^{\mathrm{a}} \mathrm{P}<0.01$, compared to pruritus group.

statistical significant differences were considered at $\mathrm{P}<0.05$. The differences were considered highly statistically significant at $\mathrm{P}<0.01$.

\section{Results}

Disease distribution of patients. The distribution of specific diseases in the patient's primary disease is shown in Fig. 1. A total of 167 cases of chronic glomerulonephritis, 77 cases of diabetic nephropathy, 58 cases of hypertensive nephropathy, 9 cases of polycystic kidney disease, 4 cases of hepatitis B associated nephritis, 2 cases of purpura nephritis, 4 cases of gout nephritis, 16 cases of lupus nephritis, 2 cases of obstructive nephropathy, 17 cases of chronic interstitial nephritis, 2 cases of unilateral renal insufficiency, 7 cases of $\operatorname{Ig} \mathrm{A}$ nephropathy, 8 cases of nephrotic syndrome, 1 case of hepatic syndrome, and 8 cases of unexplained causes were recruited in the present study.

Skin changes in the group. Among the subjects that were enrolled in the study, 197 cases had common skin itching, accounting for $51.57 \%$ of the total number (Table II; Fig. 2). A total of 109 cases of xerodermia were noted in the pruritus population and 80 cases of xerodermia were present in the non-pruritus group. A significant difference between the two groups was noted $(\mathrm{P}<0.01)$.

Clinical features of pruritus. The specific data on the pruritus statistics of the enrolled patients is presented in Table III. Moreover, no significant difference was found in the age between patients with pruritus and patients without pruritus (Table III; P>0.05 in all groups), although a signifi- 


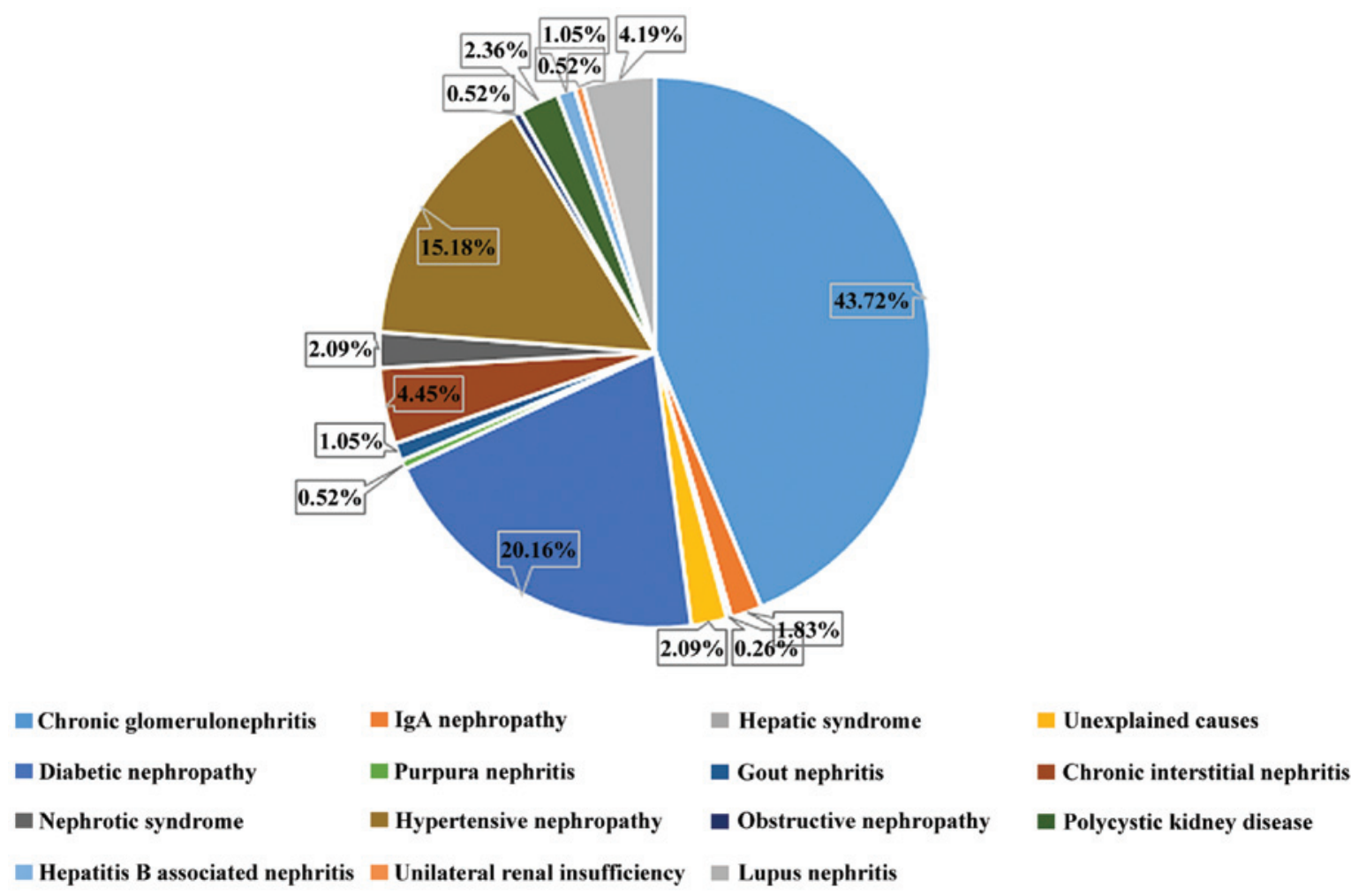

Figure 1. The distribution of specific diseases in the patient's primary disease status.

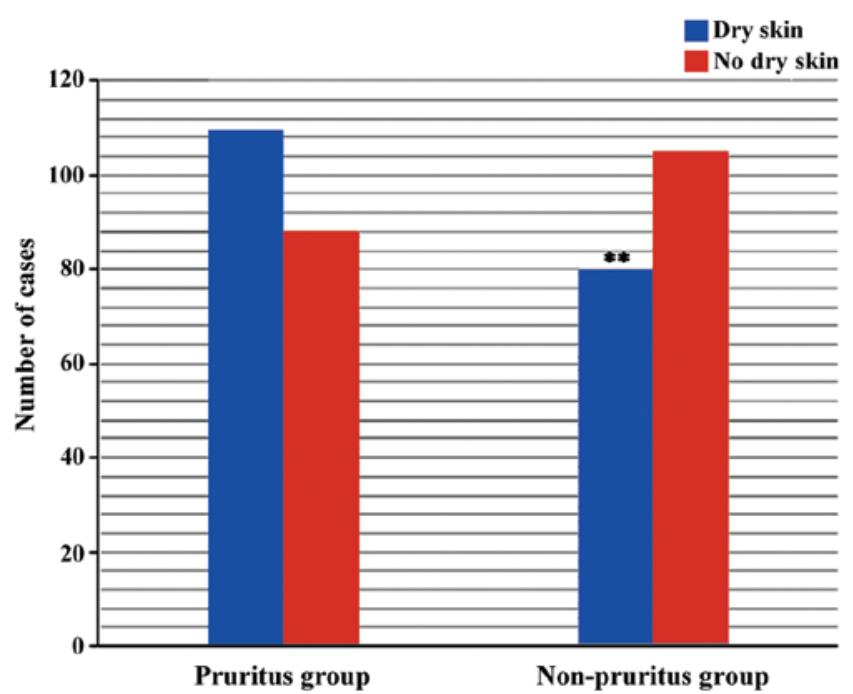

Figure 2. Distribution of skin dryness in the pruritus and non-pruritus groups. " $\mathrm{P}<0.01$.

cant difference in disease status was evident in hemodialysis patients and CRF patients $(\mathrm{P}<0.05)$. The longer the course of disease, the more likely the itching.

According to the description of the patients pruritus affected all parts of the body, and the majority of the patients exhibited pruritus symmetry. Approximately $17 \%$ of the patients had pruritus, which could affect more than $50 \%$ of the body skin. Among them, the frequency of pruritus in patients with chronic renal failure and uremia was relatively high, which exerted an emotional impact on patients. A total of 22 patients exhibited optimal conscious therapeutic effects.
Pruritus had different degrees of influence on the quality of sleep and mood of the patient (Table IV).

Cold stimuli, thermal stimuli and changes in the weather also exerted an influence on the itchiness of the patient (Table V). For both groups of patients undergoing hemodialysis and peritoneal dialysis, the symptoms of pruritus after dialysis were reduced compared to those before dialysis. The data indicated that dialysis had a certain mitigation effect on itching.

The nature of the pruritus in the patients examined exhibited a variety of associated conditions (Table VI), and with no obvious regularity in distribution. In addition, the majority of the patients did not have skin lesions when itching, but their symptoms were often accompanied by xerodermia.

Approximately $35 \%$ of patients were treated. The common treatment options included oral antihistamines and topical medications, such as compound dexamethasone acetate cream and triamcinolone acetonide. A total of 22 patients exhibited optimal conscious treatment (Table VII). The degree of pruritus in patients was assessed using visual analogue scale (Table VIII). In the course of the study, there were 28 patients with skin lesions, including scratches, blood stasis, lichenification, and prurigo nodularis.

Risk factors analysis. The levels of serum urea nitrogen, creatinine, serum phosphorus, calcium, phosphorus, and PTH were significantly different between the pruritus group and the non-pruritus group in patients with chronic renal failure (Table IX; $\mathrm{P}<0.01$ ). The pruritus intensity was correlated with increase level of serum urea nitrogen, creatinine, serum phosphorus, calcium, phosphorus, and PTH. However, the pruritus intensity was not correlated with serum calcium level $(\mathrm{P}>0.05)$. 
Table III. Distribution of patient parameters in relation with skin itching.

\begin{tabular}{|c|c|c|c|c|c|c|c|c|}
\hline \multirow[b]{2}{*}{ Parameters } & \multicolumn{2}{|c|}{ CRF patients } & \multicolumn{2}{|c|}{ Hemodialysis patients } & \multicolumn{2}{|c|}{ Peritoneal patients } & \multicolumn{2}{|c|}{ All patients } \\
\hline & $\begin{array}{l}\text { Pruritus } \\
\text { group } \\
(n=76)\end{array}$ & $\begin{array}{c}\text { Non-pruritus } \\
\text { group } \\
(\mathrm{n}=127)\end{array}$ & $\begin{array}{l}\text { Pruritus } \\
\text { group } \\
(\mathrm{n}=96)\end{array}$ & $\begin{array}{l}\text { Non-pruritus } \\
\text { group } \\
(\mathrm{n}=42)\end{array}$ & $\begin{array}{l}\text { Pruritus } \\
\text { group } \\
(n=25)\end{array}$ & $\begin{array}{l}\text { Non-pruritus } \\
\text { group } \\
(\mathrm{n}=16)\end{array}$ & $\begin{array}{l}\text { Pruritus } \\
\text { group } \\
(n=197)\end{array}$ & $\begin{array}{c}\text { Non-pruritus } \\
\text { group } \\
(n=185)\end{array}$ \\
\hline Age (years) & $52.43 \pm 16.24$ & $51.86 \pm 17.16$ & $51.56 \pm 15.33$ & $54.03 \pm 15.15$ & $49.46 \pm 14.61$ & $46.15 \pm 13.87$ & $52.26 \pm 14.86$ & $50.92 \pm 16.19$ \\
\hline Disease course & $60.63 \pm 32.27^{a}$ & $57.13 \pm 24.47$ & $44.82 \pm 18.52^{\mathrm{a}}$ & $38.04 \pm 13.58$ & $45.72 \pm 16.48$ & $39.36 \pm 20.38$ & $44.71 \pm 19.16$ & $42.69 \pm 20.37$ \\
\hline
\end{tabular}

${ }^{\mathrm{a}} \mathrm{P}<0.05$, compared to the relevant non-pruritus group.

Table IV. Relationship between psychological factors and pruritus.

\begin{tabular}{|c|c|c|c|c|c|}
\hline Parameters & $\begin{array}{l}\text { CRF patients } \\
\quad(n=76)\end{array}$ & $\begin{array}{l}\text { Hemodialysis patients } \\
\qquad(\mathrm{n}=96)\end{array}$ & $\begin{array}{l}\text { Peritoneal dialysis } \\
\text { patients }(n=25)\end{array}$ & $\chi^{2}$ value & P-value \\
\hline Sleep effects & & & & 4.472 & 0.593 \\
\hline No & 19 & 18 & 4 & & \\
\hline Mild & 31 & 46 & 12 & & \\
\hline Moderate & 21 & 25 & 6 & & \\
\hline Severe & 5 & 7 & 3 & & \\
\hline Emotional influence & & & & 6.932 & 0.316 \\
\hline No & 9 & 9 & 3 & & \\
\hline Mild & 42 & 51 & 7 & & \\
\hline Moderate & 22 & 33 & 13 & & \\
\hline Severe & 3 & 3 & 2 & & \\
\hline
\end{tabular}

Table V. Efficacy of physical methods in itching treatment.

\begin{tabular}{|c|c|c|c|c|c|}
\hline Parameters & $\begin{array}{l}\text { CRF patients } \\
\quad(n=76)\end{array}$ & $\begin{array}{l}\text { Hemodialysis patients } \\
\qquad(\mathrm{n}=96)\end{array}$ & $\begin{array}{l}\text { Peritoneal dialysis } \\
\text { patients }(n=25)\end{array}$ & $\chi^{2}$ value & P-value \\
\hline Cold stimulus & & & & 3.562 & 0.568 \\
\hline No effect & 9 & 12 & 11 & & \\
\hline Increased itching & 25 & 25 & 2 & & \\
\hline Reduced itching & 42 & 59 & 12 & & \\
\hline Thermal stimulation & & & & 3.367 & 0.542 \\
\hline No effect & 13 & 15 & 6 & & \\
\hline Increased itching & 29 & 27 & 7 & & \\
\hline Reduced itching & 34 & 54 & 12 & & \\
\hline Cold weather & & & & 2.261 & 0.342 \\
\hline No effect & 56 & 62 & 19 & & \\
\hline Increased itching & 7 & 13 & 2 & & \\
\hline Reduce itching & 13 & 21 & 4 & & \\
\hline Before dialysis & & & & 1.214 & 0.537 \\
\hline No effect & - & 61 & 18 & & \\
\hline Increased itching & - & 26 & 5 & & \\
\hline Reduce itching & - & 9 & 2 & & \\
\hline After dialysis & & & & 2.124 & 0.336 \\
\hline No effect & - & 46 & 15 & & \\
\hline Increased itching & - & 8 & 3 & & \\
\hline Reduce itching & - & 42 & 7 & & \\
\hline
\end{tabular}


Table VI. Itching type and associated lesions.

\begin{tabular}{|c|c|c|c|c|c|}
\hline Parameters & $\begin{array}{l}\text { CRF patients } \\
\quad(\mathrm{n}=76)\end{array}$ & $\begin{array}{l}\text { Hemodialysis patients } \\
\qquad(\mathrm{n}=96)\end{array}$ & $\begin{array}{l}\text { Peritoneal dialysis } \\
\text { patients }(\mathrm{n}=25)\end{array}$ & $\chi^{2}$ value & P-value \\
\hline Itching nature & & & & 4.248 & 0.627 \\
\hline No special & 28 & 40 & 13 & & \\
\hline Ant feeling & 32 & 40 & 10 & & \\
\hline Burning sensation & 6 & 7 & 1 & & \\
\hline Tingling & 10 & 9 & 1 & & \\
\hline Associated lesions & & & & 2.516 & 0.316 \\
\hline No & 62 & 85 & 20 & & \\
\hline Yes & 14 & 11 & 5 & & \\
\hline Xerodermia & & & & 2.016 & 0.338 \\
\hline No & 32 & 47 & 9 & & \\
\hline Yes & 44 & 49 & 16 & & \\
\hline
\end{tabular}

Table VII. Patient's drug treatment.

\begin{tabular}{|c|c|c|c|c|c|}
\hline Parameters & $\begin{array}{l}\text { CRF patients } \\
\quad(\mathrm{n}=76)\end{array}$ & $\begin{array}{l}\text { Hemodialysis patients } \\
\qquad(\mathrm{n}=96)\end{array}$ & $\begin{array}{l}\text { Peritoneal dialysis } \\
\text { patients }(n=25)\end{array}$ & $\chi^{2}$ value & P-value \\
\hline Treatment & & & & 5.016 & 0.082 \\
\hline No & 44 & 61 & 20 & & \\
\hline Yes & 32 & 35 & 5 & & \\
\hline Treatment effect & & & & 7.529 & 0.115 \\
\hline Cure & 5 & 11 & 1 & & \\
\hline Effective & 20 & 7 & 2 & & \\
\hline Invalid & 7 & 17 & 2 & & \\
\hline
\end{tabular}

Table VIII. Itching intensity score.

\begin{tabular}{lcccc}
\hline Itching state & State of the investigation & Worst state & Best state & Mosquito bites state \\
\hline VAS score & $3.21 \pm 1.73$ & $7.93 \pm 1.15$ & $0.47 \pm 0.35$ & $4.41 \pm 1.37$
\end{tabular}

VAS, Visual Analogue Scale.

\section{Discussion}

In patients with chronic renal failure, pruritus can occur in hemodialysis and peritoneal dialysis (17). In 2007, a study in Shanghai reported that in 478 patients with chronic renal failure, 224 were subjected to hemodialysis and peritoneal dialysis. The results indicated that the incidence of pruritus was higher in hemodialysis patients than in peritoneal dialysis patients. In the present study, the incidence of pruritus in hemodialysis patients is higher than that in peritoneal dialysis patients. This is consistent with the aforementioned findings. When uremia patients undergo routine hemodialysis, the ability of dialysis membranes to remove large and medium-sized molecules is generally poor, which can easily lead to long-term accumulation of large and medium-sized molecules (18). Peritoneal dialysis facilitates diffusion convection and ultrafiltration, and the ability to remove large and medium-sized molecules. This technique is better than hemodialysis (19).

The clinical features of pruritus are highly variable. In most patients, pruritus is symmetric, while some of them present with generalized pruritus. The data from this study suggest that uremic pruritus tends to be persistent and recurrent. The majority of the patients suffer from daily itching, while the rest of them may have itching symptoms weekly or monthly. Although pruritus tends to persist, it is not necessarily continuous, and Gilchrest also reached a similar conclusion (20). However, Ståhle-Bäckdahl et al (21) concluded that uremic pruritus has continuity. Different results may be related to differences in the sample size and the length of follow-up. The typical characteristic is that there is no obvious primary skin 
Table IX. Comparison of serum urea nitrogen, creatinine, blood calcium, phosphorus, calcium phosphorus, and PTH levels.

\begin{tabular}{|c|c|c|c|c|}
\hline Variables & Pruritus group & Non-pruritus group & t value & P-value \\
\hline \multicolumn{5}{|c|}{ Urea nitrogen $(\mathrm{mmol} / \mathrm{l})$} \\
\hline Hemodialysis & $25.35 \pm 11.45$ & $19.08 \pm 10.67$ & 3.942 & $<0.001^{\mathrm{c}}$ \\
\hline Peritoneal dialysis & $25.82 \pm 8.25$ & $24.75 \pm 13.36$ & 0.318 & 0.752 \\
\hline $\mathrm{CRF}$ & $21.24 \pm 10.68$ & $17.67 \pm 11.65$ & 2.1789 & $0.015^{\mathrm{b}}$ \\
\hline \multicolumn{5}{|l|}{ Creatinine $(\mu \mathrm{mol} / \mathrm{l})$} \\
\hline Hemodialysis & $793.63 \pm 403.36$ & $570.97 \pm 354.75$ & 4.139 & $<0.001^{\mathrm{c}}$ \\
\hline Peritoneal dialysis & $952.11 \pm 316.55$ & $812.75 \pm 246.88$ & 1.492 & 0.144 \\
\hline $\mathrm{CRF}$ & $548.92 \pm 347.83$ & $396.92 \pm 215.54$ & 3.846 & $<0.001^{\mathrm{c}}$ \\
\hline \multicolumn{5}{|c|}{ Blood calcium (mmol/l) } \\
\hline Hemodialysis & $1.98 \pm 0.32$ & $2.09 \pm 0.21$ & -2.956 & $0.003^{\mathrm{c}}$ \\
\hline Peritoneal dialysis & $1.97 \pm 0.27$ & $2.01 \pm 0.29$ & -0.450 & 0.656 \\
\hline CRF & $2.01 \pm 0.31$ & $2.05 \pm 0.23$ & -1.050 & 0.295 \\
\hline \multicolumn{5}{|l|}{ Phosphorus (mmol/l) } \\
\hline Hemodialysis & $1.97 \pm 0.57$ & $1.65 \pm 0.67$ & 3.477 & $<0.001^{\mathrm{c}}$ \\
\hline Peritoneal dialysis & $1.88 \pm 0.61$ & $1.86 \pm 0.62$ & 0.102 & 0.919 \\
\hline $\mathrm{CRF}$ & $1.68 \pm 0.59$ & $1.55 \pm 0.59$ & 1.519 & 0.130 \\
\hline \multicolumn{5}{|l|}{ Calcium x phosphorus } \\
\hline Hemodialysis & $3.83 \pm 1.68$ & $3.36 \pm 1.46$ & 2.097 & $0.037^{\mathrm{a}}$ \\
\hline Peritoneal dialysis & $3.62 \pm 1.14$ & $3.77 \pm 1.25$ & -0.396 & 0.694 \\
\hline $\mathrm{CRF}$ & $3.35 \pm 1.06$ & $3.28 \pm 1.20$ & 0.420 & 0.675 \\
\hline \multicolumn{5}{|l|}{ PTH (pg/ml) } \\
\hline Hemodialysis & $608.15 \pm 514.44$ & $243.46 \pm 206.55$ & 7.099 & $<0.001^{\mathrm{c}}$ \\
\hline Peritoneal dialysis & $677.34 \pm 445.74$ & $373.75 \pm 226.28$ & 2.517 & $0.016^{\mathrm{b}}$ \\
\hline CRF & $447.61 \pm 415.76$ & $236.26 \pm 203.11$ & 4.845 & $<0.001^{\mathrm{c}}$ \\
\hline
\end{tabular}

${ }^{\mathrm{a}} \mathrm{P}<0.05,{ }^{\mathrm{b}} \mathrm{P}<0.01,{ }^{\mathrm{c}} \mathrm{P}<0.001$.

lesion, although patients with chronic renal failure secondary to diabetes usually develop hyperkeratotic nodules. Their pathology suggests that penetrating skin diseases can produce strong and persistent skin itching (22). In addition, various factors affect skin itching, although two of them are mainly responsible for aggravating this process: heat and dryness. Different temperatures exert different effects on pruritus. An appropriate increase in water temperature can increase pruritus, although it can be relieved at approximately $40^{\circ} \mathrm{C}$. This is mainly due to hyperthermia, which stimulates painsensing nerves and blocks the symptoms of pruritus. High temperatures can further cause histamine release and increase itching. Although this process does not aggravate pruritus in high temperatures, it is possibly caused, since histamine does not play a major role in pruritus $(23,24)$.

Xerodermia is mainly manifested as dark skin without moisture, scaling, visible small cracks and dry cracks, which occur in the extensor side of the limbs. Some studies have shown that (25) xerodermia is closely related to pruritus. The reasons are the following: changes in skin barrier function, accumulation of metabolites in patients with chronic renal failure and increased secretion of urea in sweat. The aforementioned processes interfere with the activation of ACE (Angiotensin converting enzyme) (26) and lead to impaired skin function. The impaired function of sebaceous and sweat glands, the dysfunction of sebaceous glands and the apocrine sweat glands in patients with chronic renal failure are some of the reasons that lead to xerodermia. The increase in the $\mathrm{pH}$ of the stratum corneum of the skin and the increase of vitamin A concentration in the epidermis are also considered pathogenic causes of xerodermia.

Currently, the pathogenesis of uremic pruritus is not clear, but the hypotheses that are related to the pathogenesis of pruritus are the following: immune function disorder hypothesis, opioid hypothesis, parathyroid hormone hypothesis, bivalent ion hypothesis and molecular hypothesis. Thus it is very difficult to imply that itching is caused by a single factor (27).

The glomerular filtration function of patients with chronic renal failure was reduced, and the residual renal units did not excrete metabolites adequatly, which caused the product to accumulate in the body and exert toxic effects. Chronic renal failure is a complex pathophysiological process that is usually responsible for a series of complications, such as calcium and phosphorus metabolism disorders. When the concentration of blood phosphorus increases, it combines with blood calcium to form calcium phosphate, which will be deposited on the skin and other tissues to reduce blood calcium. Hypocalcemia can 
also promote secondary hyperparathyroidism and as a result cause higher secretion of parathyroid hormone (PTH). PTH causes renal tubular reabsorption of phosphorus and regulates blood phosphorus levels. In the present study, it was found that the levels of urea, creatinine, serum phosphorus, calcium, phosphorus, and PTH in patients with itching were significantly higher than those in people without itching $(\mathrm{P}<0.05)$. This suggests that they play a key role in the pathogenesis of uremia.

In addition, secondary hyperparathyroidism is a common disorder in patients with chronic renal failure. It has been reported (28) that pruritus can be relieved after total parathyroidectomy. However, not all uremic patients suffering from pruritus have hyperparathyroidism. In some patients, itching determined by parathyroid hormone is still not in remission after parathyroidectomy. Injecting PTH into the human body does not cause pruritus, suggesting that PTH itself has no itching effect (29). Therefore, unless combined with hyperparathyroidism, parathyroidectomy is not effective in the treatment of uremic pruritus.

The results of the present study demonstrate that the majority of patients with chronic renal failure and uremia suffer from itching. The occurrence of pruritus is related to the course of the disease and not to age or sex. Xerodermia is the most common skin manifestation in patients with chronic renal failure. It is related to the occurrence of itching. The itching site and duration are different. Local cold or heat stimuli and reduced temperatures can, to some extent, relieve itching. In addition, adequate hemodialysis can also relieve itching. The levels of serum urea nitrogen, creatinine, serum phosphorus, calcium-phosphorus product, and PTH were associated with the occurrence of pruritus.

\section{Acknowledgements}

Not applicable.

\section{Funding}

No funding was received.

\section{Availability of data and materials}

The datasets used and/or analyzed during the current study are available from the corresponding author on reasonable request.

\section{Authors' contributions}

TH and SW contributed to the conception and design of the study. TH and BW were responsible for the collection and assembly of the data. XL completed the data analysis and interpretation. TH and SW were involved in writing of the manuscript. All authors read and approved the final manuscript.

\section{Ethics approval and consent to participate}

The study was approved by the Ethics Committee of the Second Affiliated Hospital of Chongqing Medical University (Chongqing, China). All patients included in the study provided written informed consent for their participation.

\section{Patient consent for publication}

Not applicable.

\section{Competing interests}

The authors declare that they have no competing interests.

\section{References}

1. Tanaka K, Tani Y, Asai J, Nemoto F, Kusano Y, Suzuki H, Hayashi Y, Asahi K, Katoh T, Miyata T, et al: Skin autofluorescence is associated with renal function and cardiovascular diseases in pre-dialysis chronic kidney disease patients. Nephrol Dial Transplant 26: 214-220, 2011.

2. Chao CC, Wu VC, Tan CH, Wang YM, Tseng MT, Wu PC, Lin YH, Lin WM, Wu KD and Hsieh ST: Skin denervation and its clinical significance in late-stage chronic kidney disease. Arch Neurol 68: 200-206, 2011.

3. Cioboată R, Găman A, Traşcă D, Ungureanu A, Docea AO, Tomescu P, Gherghina F, Arsene AL, Badiu C, Tsatsakis AM, et al: Pharmacological management of non-alcoholic fatty liver disease: Atorvastatin versus pentoxifylline. Exp Ther Med 13: 2375-2381, 2017.

4. Wojciechowski VV, Calina D, Tsarouhas K, Pivnik AV, Sergievich AA, Kodintsev VV, Filatova EA, Ozcagli E, Docea AO, Arsene AL, et al: A guide to acquired vitamin K coagulophathy diagnosis and treatment: The Russian perspective. Daru 25: 10, 2017.

5. Ungureanu A, Zlatian O, Mitroi G, Drocaş A, Ţîrcă T, Călina D, Dehelean C, Docea AO, Izotov BN, Rakitskii VN, et al: Staphylococcus aureus colonisation in patients from a primary regional hospital. Mol Med Rep 16: 8771-8780, 2017.

6. Tripathi T, Shahid M, Raza A, Khan HM, Khan RA, Mahdi AA, Siddiqui M, Malik A and Khan AA: Dose-dependent effect of histamine on liver function markers in immunized rabbits. Exp Toxicol Pathol 64: 875-881, 2012.

7. Yosipovitch G, Duque MI, Patel TS, Ishiuji Y, Guzman-Sanchez DA, Dawn AG, Freedman BI, Chan YH, Crumrine D and Elias PM: Skin barrier structure and function and their relationship to pruritus in end-stage renal disease. Nephrol Dial Transplant 22: 3268-3272, 2007.

8. Francos GC, Kauh YC, Gittlen SD, Schulman ES, Besarab A, Goyal S and Burke JF Jr: Elevated plasma histamine in chronic uremia. Effects of ketotifen on pruritus. Int J Dermatol 30: 884-889, 1991.

9. Nordal EJ and Os I: Uremic pruritus - pathogenesis and treatment. Tidsskr Nor Laegeforen 127: 1201-1203, 2007 (In Norwegian).

10. Namazi MR, Fallahzadeh MK and Roozbeh J: Nicotinamide as a potential novel addition to the anti-uremic pruritus weaponry. Saudi J Kidney Dis Transpl 20: 291-292, 2009.

11. Mahmudpour M, Roozbeh J, Raiss Jalali GA, Pakfetrat M, Ezzat Zadegan S and Sagheb MM: Therapeutic effect of montelukast for treatment of uremic pruritus in hemodialysis patients. Iran J Kidney Dis 11: 50-55, 2017.

12. Wang WY, Tarng DC, Chiang LC, Chu CM and Wang KY: Evaluation of uraemic pruritus in long-term dialysis patients using a modified Chinese scale. Nephrology (Carlton) 20: 632-638, 2015.

13. Min JW, Kim SH, Kim YO, Jin DC, Song HC, Choi EJ, Kim YL, Kim YS, Kang SW, Kim NH, et al: Comparison of uremic pruritus between patients undergoing hemodialysis and peritoneal dialysis. Kidney Res Clin Pract 35: 107-113, 2016.

14. Roh SY and Kim KH: Effects of aroma massage on pruritus, skin $\mathrm{pH}$, skin hydration and sleep in elders in long-term care hospitals. J Korean Acad Nurs 43: 726-735, 2013 (In Korean).

15. Nattkemper LA, Lee HG, Valdes-Rodriguez R, Mollanazar NK, Sanders KM and Yosipovitch G: Cholinergic induction of perspiration attenuates nonhistaminergic pruritus in the skin of patients with atopic dermatitis and healthy controls. Br J Dermatol 173: 282-284, 2015.

16. Suseł J, Batycka-Baran A, Reich A and Szepietowski JC: Uraemic pruritus markedly affects the quality of life and depressive symptoms in haemodialysis patients with end-stage renal disease. Acta Derm Venereol 94: 276-281, 2014. 
17. Durrant-Finn U, Osten B, Mügge $C$ and Nenoff P: Pruritus and dryness of the skin in chronic kidney insufficiency and dialysis patients - a review. Wien Med Wochenschr 159: 317-326, 2009 (In German)

18. Zakrzewska-Pniewska B and Jedras M: Is pruritus in chronic uremic patients related to peripheral somatic and autonomic neuropathy? Study by R-R interval variation test (RRIV) and by sympathetic skin response (SSR). Neurophysiol Clin 31: 181-193, 2001.

19. Momose A, Kudo S, Sato M, Saito H, Nagai K, Katabira Y and Funyu T: Calcium ions are abnormally distributed in the skin of haemodialysis patients with uraemic pruritus. Nephrol Dial Transplant 19: 2061-2066, 2004.

20. Gilchrest BA, Stern RS, Steinman TI, Brown RS, Arndt KA and Anderson WW: Clinical features of pruritus among patients undergoing maintenance hemodialysis. Arch Dermatol 118: $154-156,1982$.

21. Ståhle-Bäckdahl M, Hägermark O, Lins LE, Törring O, Hilliges $\mathrm{M}$ and Johansson $\mathrm{O}$ : Experimental and immunohistochemical studies on the possible role of parathyroid hormone in uraemic pruritus. J Intern Med 225: 411-415, 1989.

22. Haest C, Casaer MP, Daems A, De Vos B, Vermeersch E, Morren MA, Van Steenbergen W, Ceuppens JL and Moons P: Measurement of itching: Validation of the Leuven itch scale. Burns 37: 939-950, 2011.

23. Wu HY, Peng YS, Chen HY, Tsai WC, Yang JY, Hsu SP, Pai MF, Lu HM, Chiang JF, Ko MJ, et al: A comparison of uremic pruritus in patients receiving peritoneal dialysis and hemodialysis. Medicine (Baltimore) 95: e2935, 2016.
24. Lou H, Lu J, Choi EB, Oh MH, Jeong M, Barmettler S, Zhu Z and Zheng T: Expression of IL-22 in the skin causes Th2-biased immunity, epidermal barrier dysfunction, and pruritus via stimulating epithelial Th2 cytokines and the GRP pathway. J Immunol 198: 2543-2555, 2017.

25. Park BK, Park YC, Jung IC, Kim SH, Choi JJ, Do M, Kim SY and Jin M: Gamisasangja-tang suppresses pruritus and atopic skin inflammation in the NC/Nga murine model of atopic dermatitis. J Ethnopharmacol 165: 54-60, 2015.

26. Quinlivan R, Mitsuahashi S, Sewry C, Cirak S, Aoyama C, Mooore D, Abbs S, Robb S, Newton T, Moss C, et al: Muscular dystrophy with large mitochondria associated with mutations in the CHKB gene in three British patients: Extending the clinical and pathological phenotype. Neuromuscul Disord 23: 549-556, 2013.

27. Wikström B, Gellert R, Ladefoged SD, Danda Y, Akai M, Ide K, Ogasawara M, Kawashima Y, Ueno K, Mori A, et al: Kappa-opioid system in uremic pruritus: Multicenter, randomized, double-blind, placebo-controlled clinical studies. J Am Soc Nephrol 16: 3742-3747, 2005.

28. Makhlough A, Emadi N, Sedighi O, Khademloo M and Bicmohamadi AR: Relationship between serum intact parathyroid hormone and pruritus in hemodialysis patients. Iran J Kidney Dis 7: 42-46, 2013.

29. Weenig RH, Sewell LD, Davis MDP, McCarthy JT and Pittelkow MR: Calciphylaxis: Natural history, risk factor analysis, and outcome. J Am Acad Dermatol 56: 569-579, 2007. 